\title{
Water sorption, solubility and surface roughness of resin surface sealants
}

\author{
Jaqueline Biazuz ${ }^{1}$, Patrícia Zardo ${ }^{1}$, Sinval Adalberto Rodrigues-Junior ${ }^{1}$
}

${ }^{1}$ Universidade Comunitária da Região de Chapecó - UNOCHAPECÓ, School of Dentistry, Area of Restorative Dentistry, Chapecó - SC - Brazil

\begin{abstract}
Surface sealants have been suggested as final glaze of the surface of composite restorations. However, little is known about bulk and surface properties of these materials aiming the long-term preservation of the surface integrity of these restorations. Aim: To evaluate the water sorption, solubility and surface roughness of commercial surface sealants for restorations. Methods: Five disc-shaped specimens ( $15 \mathrm{~mm}$ diameter $X 1 \mathrm{~mm}$ high) were made from the surface sealants Natural Glaze (DFL) and Permaseal (Ultradent) and were light cured according to the manufacturer's instructions. The specimens were finished with 1500-grit SiC paper. Water sorption (WS) and solubility (SL) were assessed as recommended by the ISO 4049/2000 and were expressed in $\mu \mathrm{g} / \mathrm{mm}^{3}$. Surface roughness was evaluated before and after WS and SL, and was expressed in $\mu \mathrm{m}$ as $R_{1}$ (before WS and $S L$ ) and $R_{2}$ (after WS and $S L$ ). It was obtained from three parallel measurements along a $4 \mathrm{~mm}$ length. Data were analyzed using t-test and paired t-test $(\alpha=0.05)$. Results: Water sorption and solubility of Natural Glaze were significantly lower than that of Permaseal $(p<0.05)$. Degradation of the surface sealants did not affect significantly their surface roughness $(p>0.05)$. Conclusions: Surface sealants used in composite restorations undergo hydrolytic degradation; however, this degradation seems not to interfere on surface roughness of these materials.
\end{abstract}

Keywords: composite resins; solubility; dental restoration, permanent.

\section{Introduction}

The quality of the restoration surface is rather important for its longevity, as it affects anatomic form, color stability, surface roughness and luster of the restoration ${ }^{1}$. It may also influence the speed of water diffusion into the material bulk and its potential degradation. Besides, a smooth surface tends to withstand better the wear imposed by tooth brushing and occlusal contact with antagonist teeth or food during mastication ${ }^{2}$.

Restorations are submitted to finishing and polishing procedures in an attempt

Received for publication: January 16, 2015 Accepted: March 04, 2015

Correspondence to: Sinval Adalberto Rodrigues-Junior Universidade Comunitária da Região de Chapecó Área de Ciências da Saúde Caixa Postal 1141

Av. Senador Atílio Fontana, n. 591-E - Efapi CEP 89809-000 - Chapecó - SC - Brasil Phone: +55 49 3321-8069

E-mail: rodriguesjunior.sa@unochapeco.edu.br to achieve a smooth surface. The finishing procedures aim at the removal and gross contouring of the restorations and the polishing aims at reducing the roughness of the surface and removing grooves and scratches produced by the finishing instruments. Finishing is usually performed with diamond or tungsten carbide finishing burs and polishing is done by abrasive impregnated cups, points and disks ${ }^{3}$.

Some manufacturers recommend the use of a felt disk associated to an abrasive paste for final luster, while others advise a final glaze by applying a resin surface sealant. Söderholm et al. ${ }^{4}$ (1984) suggested that micro-fissures and micro-cracks are generated during finishing/polishing procedures, which would accelerate water 
diffusion and surface deterioration, the use of resin sealant being an attempt to fill these defects, as it would preserve the integrity of the surface and improve the longevity of the restoration ${ }^{5-7}$.

However, the use of resin surface sealants to improve the quality of composite restorations is still controversial ${ }^{5,8}$. Dental literature has few studies regarding the surface sealant's properties and the effect of moisture on them. Most surface sealants are constituted by the same dimethacrylatebased substance used in dental composites, and they have no reinforcing fillers 9 . Therefore, water diffusion may affect the sealant in a similar way it affects composite restoratives, which would compromise physical properties important to maintain the integrity of the surface. Also, up to the present moment, it is not known whether surface sealants degrade similarly to each other, as they may be composed by different dimethacrylate molecules and proportions.

Understanding the properties of the sealants may help to identify whether using surface sealants is beneficial for the long-term durability of the restorations, which is of utmost importance, as the application of surface sealants represent additional time and cost for both, clinician and patient ${ }^{5}$. Therefore, this study evaluated some properties of the resin surface sealants and tested the following hypotheses: a) water sorption and solubility of the surface sealants will be different, given the differences in their constitution; b) surface roughness will increase after water sorption and solubility, with no difference between sealants.

\section{Material and methods}

Five specimens of each surface sealant (Table 1) were made using a stainless steel mold with $15 \mathrm{~mm}$ diameter $\mathrm{X} 1$ $\mathrm{mm}$ thick. The specimens were built according to the ISO $4049^{10}$ for evaluating surface roughness, water sorption and solubility, and they were light cured for the time recommended by the manufacturer (Table 1). The structure of the monomer molecules that constitute the surface sealants is depicted in Figure 1. Eighteen superposed light exposures were performed, nine on the top surface and nine on the bottom surface of the specimen (Figure 2). A LED light curing unit (Ultraled, Dabi Atlante, Ribeirão Preto, SP, Brazil) was used and had its light irradiance measured $\left(\sim 650 \mathrm{~mW} / \mathrm{cm}^{2}\right)$ at the beginning and at the end of the session with a LED radiometer (Ecel, Ribeirão Preto, SP, Brazil).

The specimens were removed from the mold and were finished using a 1500 grit $\mathrm{SiC}$ paper. Thickness was averaged from five measurements (four at border of the specimen and one at the center) using a digital caliper (Mitutoyo Corporation, Kanagawa, Japan). The diameter was averaged from two measurements ${ }^{10}$, and was used to calculate the

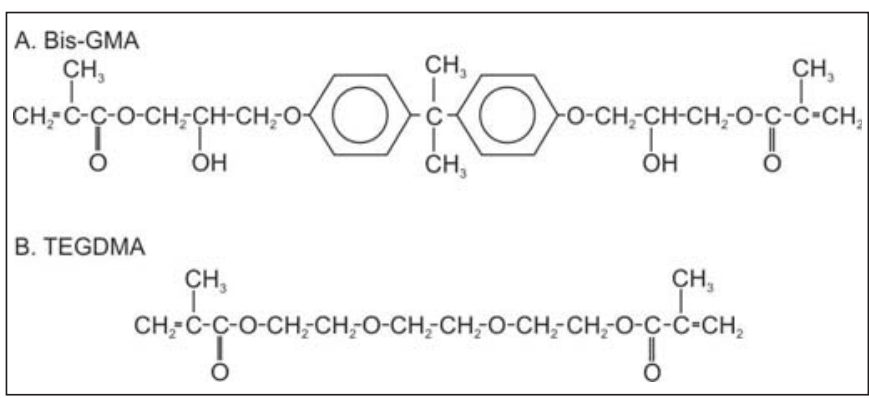

Fig. 1. Monomers constituting the surface sealants

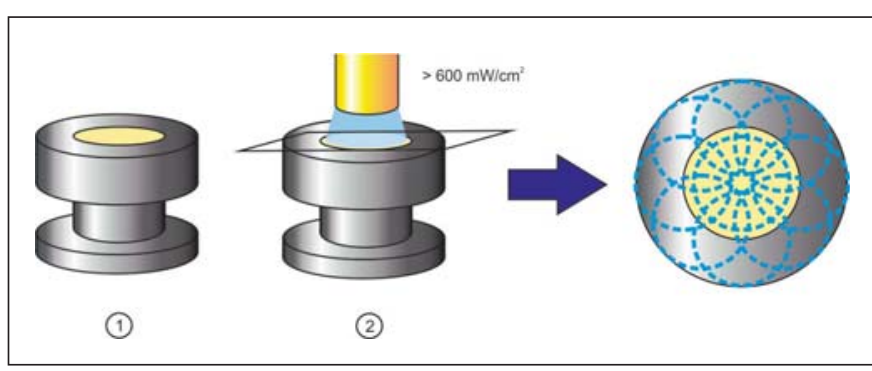

Fig. 2. Light-curing procedure

volume of the specimens $\left(R=D m / 2\right.$ and $\left.V=\pi \cdot R^{2} \cdot h\right)$, where $\mathrm{R}$ is the radius of the specimen; $\mathrm{Dm}$ is the mean diameter, $\mathrm{V}$ is the volume, and $\mathrm{h}$ is the height of the specimen. The specimens were stored in a desiccator at $37{ }^{\circ} \mathrm{C}$ with silica gel and weighed daily until their mass was stabilized (dry mass, $\left.\mathrm{m}_{1}\right)$. The specimens were then stored in distilled water for 7 days to obtain the wet mass $\left(\mathrm{m}_{2}\right)$. Thereafter, the specimens were again stored in the desiccator at $37{ }^{\circ} \mathrm{C}$, and reweighed until a constant dry mass $\left(\mathrm{m}_{3}\right)$ was attained. Weighing was performed with an analytical balance with $0.1 \mathrm{mg}$ accuracy (AUW220D; Shimadzu Corporation, Kyoto, Japan). Water sorption (WS) and solubility (SL) were calculated using the following equations: WS $=\left(\mathrm{m}_{2}-\mathrm{m}_{3}\right) /$ $\mathrm{V} ; \mathrm{SL}=\left(\mathrm{m}_{1}-\mathrm{m}_{3}\right) / \mathrm{V}$, and were expressed in $\mu \mathrm{g} / \mathrm{mm}^{3}$.

Surface roughness (Ra) was measured and averaged from three parallel measurements along a $4 \mathrm{~mm}$ length with a cut off setting of $0.8 \mathrm{~mm}$ using a profilometer (RP200 Roughness Meter; Instrutherm, São Paulo, SP, Brazil). Surface roughness was measured before and after water sorption and solubility.

Data of water sorption and solubility between sealants were analyzed using t-test $(\alpha=0.05)$, while data of surface roughness of each sealant before and after water sorption and solubility were analyzed with paired t-test $(\alpha=0.05)$.

\section{Results}

The results of water sorption, solubility and surface roughness of the surface sealants evaluated in this study are presented in Table 2 (mean and standard deviation). T-test

Table 1. Surface sealants assessed in the study

\begin{tabular}{lllcc}
\hline Surface sealant & Manufacturer & Composition & Light curing time & Batch no. \\
Natural & Glaze DFL & Bis-GMA, TEGDMA & $20 \mathrm{~s}$ & 13030488 \\
Permaseal & Ultradent & Bis-GMA & $20 \mathrm{~s}$ & B8RPF \\
\hline
\end{tabular}


Table 2. Water sorption, solubility and surface roughness of the surface sealants

\begin{tabular}{lllll}
\hline Surface sealant & \multicolumn{2}{c}{ Water sorption and solubility $\left(\mu \mathrm{g} / \mathrm{mm}^{3}\right)$} & \multicolumn{2}{c}{ Surface roughness $(\mu \mathrm{m})$} \\
& WS & $\mathrm{SL}$ & $\mathrm{Ra}_{1}$ & $\mathrm{Ra}_{2}$ \\
Natural Glaze & $4.008 \times 10^{-5}$ & $1.731 \times 10^{-6}$ & 0.1776 & 0.1328 \\
& $\left(0.205 \times 10^{-5}\right)$ & $\left(0.132 \times 10^{-6}\right)$ & $(0.0861)$ & $(0.0591)$ \\
Permaseal & $5.183 \times 10^{-5}$ & $2.698 \times 10^{-6}$ & 0.1624 & 0.1108 \\
& $\left(0.234 \times 10^{-5}\right)$ & $\left(0.299 \times 10^{-6}\right)$ & $(0.0333)$ & $(0.0486)$ \\
\hline
\end{tabular}

revealed that Permaseal presented higher water sorption $(\mathrm{p}<0.0001)$ and solubility $(\mathrm{p}<0.001)$ than Natural Glaze. The paired t-test revealed that water sorption and solubility did not affect the surface roughness of Natural Glaze $(p<0.229)$ and Permaseal $(p<0.142)$.

\section{Discussion}

The phenomena of water sorption and solubility are part of the degradation process of restorative materials based on the dimethacrylate chemistry, which ultimately lead to a more porous and fragile restoration ${ }^{11}$. Hydrolytic degradation has been described as the cleavage process of linkage that form polymers, generating oligomers and, finally, monomers ${ }^{12-13}$. According to Gopferich ${ }^{13}$ (1996), this process is triggered by water infiltration within the polymeric chains. Factors such as the hydrophilic nature of polymer, differences in the solubility parameter between the polymer and the solvent, cross-link density and filler are understood as important to determine the extension of the polymer degradation in the aqueous environment ${ }^{11,14}$.

The first hypothesis of this study was accepted, since the water sorption and solubility behavior of the studied sealants presented different results. This may be explained by their constitution, which involves two out of the three most used monomers in dental restorative composites: BisGMA (2, 2-bis[4-(20-hydroxy-30-methacryloxypropoxy) phenil]propane) and TEGDMA (triethyleneglycoldime thacrylate). The Bis-GMA polymer presents superior mechanical properties when compared to the others. The voluminous aromatic rings in the molecule structure are responsible for the Bis-GMA's stiffness ${ }^{15}$ and for a lower degree of conversion of the resulting polymer. On the other hand, a larger network is formed by TEGDMA, whose molecules are smaller, therefore more mobile and in higher amount ${ }^{16}$. This network, in spite of being denser, is also spatially more heterogeneous, presenting parts with higher cross-link density and parts with lower cross-link density, which are particularly more prone to water sorption ${ }^{17-18}$.

Both molecules present polar linkages with affinity to water. Hydroxyl groups are responsible for the hydrophilic character in Bis-GMA, while in TEGDMA the ether linkages are those that attract water ${ }^{11}$. Studies have shown that water sorption by TEGDMA is higher than by Bis-GMA ${ }^{11,17}$.

The type of monomer also determines the degree of conversion and the cross-link density of the resulting polymer network and, as a consequence, the degree of deterioration of the material ${ }^{11}$. For instance, the polymer resulting from a monomer blend based exclusively on Bis-GMA presents a lower degree of conversion due to the rigidity of the monomer, impairing the union of a polymerizable methacrylate group with another ${ }^{15}$. The incorporation of TEGDMA monomers to this blend increases the conversion degree due to its high mobility. Also, the higher amount of TEGDMA monomers proportional to Bis-GMA increases the extent and the degree of reticulation of the resulting polymer, reducing its susceptibility to water penetration and solubilization ${ }^{11,19}$

This may explain the lower water sorption and solubility of Natural Glaze when compared to Permaseal, as the former is constituted by Bis-GMA and TEGDMA and most likely formed a denser polymer by the presence of this monomer ${ }^{16-17}$. Sideridou, Tserki and Papanastasiou ${ }^{17}$ (2003) compared the degree of conversion, water sorption and solubility of a polymer blend formed exclusively by Bis-GMA and by the combination of Bis-GMA/TEGDMA in 50/50 wt $\%$ and $70 / 30 \mathrm{wt} \%$. Both combinations of Bis-GMA/TEGDMA presented higher degree of conversion than the Bis-GMA alone. Besides, they also presented higher water sorption and lower solubility than BisGMA. The amount of water percolating within the material seems to depend on the percentage of TEGDMA in a Bis-GMA/ TEGDMA co-polymer, becoming higher with increase of percentage $^{12}$. Still, TEGDMA has been shown to be less eluted than Bis-GMA in a Bis-GMA/TEGDMA copolymer ${ }^{17}$.

None of the sealants studied present inorganic filler. The presence of filler may reduce the amount of water sorption and solubility, since it reduces the amount of organic matrix ${ }^{16}$. Besides, the surface of the silanized filler particles is inert and does not absorb fluids?.

The initial surface roughness of the sealants was determined by polishing with a 1500 -grit $\mathrm{SiC}$ paper and was inferior to the threshold for bacterial biofilm accumulation of $0,2 \mu \mathrm{m}^{20}$ for both sealants. As to the final surface roughness, following water sorption and solubility, one could expect that surface sealants constituted by the same monomers as the composites and with no filler would be increased as consequence of the material deterioration and increase in porosity. Nevertheless, surface roughness did not differ significantly from the initial roughness for neither of the sealants, leading to the rejection of the second hypothesis.

The increase of surface roughness results from the solubilization process, which in dental composites involves the lixiviation of non-converted monomers, oligomers, catalysts, silane and other by-products ${ }^{20-22}$. Furthermore, this process exposes and dislodges filler particles from the material's surface, contributing to a rougher surface in composites $^{21}$. 
Even so, the final surface roughness of the sealants in absolute numbers was reduced in $\sim 0.05 \mu \mathrm{m}$. An explanation may be that this reduction may have been caused by absence of filler load in the material, and roughness resulting from the solubilization process would reflect the regularization of small surface irregularities remaining after abrasion with the $\mathrm{SiC}$ paper and lixiviation of molecules, whose size did not impact the final roughness. However, this study did not assess the effect of the solubilization process on the surface roughness following additional abrasive challenge, such as the one caused by tooth brushing or mastication ${ }^{20}$.

Although surface sealants have been available on the dental market for over 20 years, no previous study had characterized the hydrolytic degradation properties of these materials in view of the maintenance or improvement of the service life of composite restorations. For instance, this rationale should be applied in principle to all materials introduced in the dental market. Further research should involve surface sealants containing filler particles and sealants constituted by monomers other than dimethacrylates. Dimethacrylate-based surface sealants present different water sorption and solubility due to their different organic composition. Surface roughness seemed not to be affected by water sorption and solubilization.

\section{References}

1. Rodrigues-Junior SA, Chemin P, Piaia PP, Ferracane JL. Surface roughness and gloss of actual composites as polished with different polishing systems. Oper Dent. 2014 Sep 30 [In press].

2. Voltarelli FR, Santos Daroz CB, Alves MC, Cavalcanti AN, Marchi GM. Effect of chemical degradation followed by toothbrushing on the surface roughness of restorative composites. J Appl Oral Sci. 2010; 18: 585-90.

3. Çelik Ç, Özgünaltay G. Effect of finishing and polishing procedures on the surface roughness of tooth-colored materials. Quintessence Int. 2009; 40: 783-9.

4. Söderholm KJ, Zigan M, Ragan M, Fischlschweiger W, Bergman M. Hydrolytic degradation of dental composites. J Dent Res. 1984; 63: 1248-54.

5. Cilli R, Mattos MCR, Honorio HM, Rios D, Araujo PA, Prakki A. The role of surface sealants in the roughness of composites after a simulated toothbrushing test. J Dent. 2009; 37: 970-7.

6. Dickinson GL, Leinfelder KF, Mazer RB, Russell CM. Effect of surface penetrating sealant on wear rate of posterior composite resins. JAm Dent Assoc. 1990; 121: 251-5.

7. Fonseca AS, Gerardt LM, Pereira GD, Sinhoreti MA, Schneider LF. Do new matrix formulations improve resin composite resistance to degradation processes? Braz Oral Res. 2013; 27: 410-6.

8. Lopes MB, Saquy PC, Moura SK, Wang L, Graciano FMO, Correr Sobrinho $L$, et al. Effect of different surface penetrating sealants on the roughness of a nanofiller composite resin. Braz Dent J. 2012; 23: 692-7.

9. Valentini F, Oliveira SGD, Guimarães GZ, Barbosa RPS, Moraes RR. Effect of surface sealant on the color stability of composite resin restorations. Braz Dent J. 2011; 22: 365-8.

10. International Standards Organization ISO 4049. Dentistry - Polymerbased filling, restorative and luting materials: 2000 .

11. Ferracane JL. Hygroscopic and hydrolytic effects in dental polymer networks. Dent Mater. 2006; 22: 211-22.

12. Bagheri R, Tyas MJ, Burrow MF. Subsurface degradation of resin-based composites. Dent Mater. 2007; 23: 944-51.
13. Gopferich A. Mechanisms of polymer degradation and erosion. Biomaterials.1996; 17: 103-14.

14. Sideridou ID, Karabela MM. Sorption of water, ethanol or ethanol/water solutions by light-cured dental dimethacrylate resins. Dent Mater. 2011; 27: 1003-10.

15. Van Landuyt KL, Snauwaert J, De Munck J, Peumans M, Yoshida Y, Poitevin A et al. Systematic review of the chemical composition of contemporary dental adhesives. Biomaterials. 2007; 28: 3757-85.

16. Sideridou ID, Achilias DS. Elution study of unreacted Bis-GMA, TEGDMA, UDMA, and Bis-EMA from light-cured dental resins and resin composites using HPLC. J Biomed Mater Res Part B: Appl Biomater. 2005; 74B: 617-26.

17. Cramer NB, Stansbury JW, Bowman CN. Recent advances and developments in composite dental restorative materials. J Dent Res. 2011; 90: 402-16.

18. Sideridou I, Tserki V, Papanastasiou G. Study of water sorption, solubility and modulus of elasticity of light-cured dimethacrylate-based dental resins. Biomaterials. 2003; 24: 655-65.

19. Gajewski VES, Pfeifer CS, Fróes-Salgado NRG, Boaro LCC, Braga RR. Monomers used in resin composites: degree of conversion, mechanical properties and water sorption/solubility. Braz Dent J. 2012 23: 508-14.

20. Ferracane JL. Resin composite - State of the art. Dent Mater. 2011; 27: 29-38.

21. Münchow EA, Ferreira ACA, Machado RMM, Ramos TS, RodriguesJunior SA, Zanchi $\mathrm{CH}$. Effect of acidic solutions on the surface degradation of a micro-hybrid composite resin. Braz Dent J. 2014; 25: 321-6.

22. Van Landuyt KL, Nawrot T, Geebelen B, De Munck J, Snauwaert J, Yoshihara K, et al. How much do resin-based dental materials release? A meta-analytical approach. Dent Mater. 2011; 27: 723-47. 